\title{
Universal generating function based probabilistic production simulation for wind power integrated power systems
}

\author{
Tingchao JIN ${ }^{1}$, Ming ZHOU ${ }^{1}$, Gengyin LI $^{1}$
}

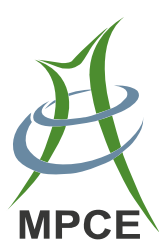

\begin{abstract}
According to the demand of sustainable development and low-carbon electricity, it is important to develop clean resources and optimize scheduling generation mix. Firstly, a novel method for probabilistic production simulation for wind power integrated power systems is proposed based on universal generating function (UGF), which completes the production simulation with the chronological wind power and load demand. Secondly, multiple-period multiple-state wind power model and multiple-state thermal unit power model are adopted, and both thermal power and wind power are coordinately scheduled by the comprehensive cost including economic cost and environmental cost. Furthermore, the accommodation and curtailment of wind power is synergistically considered according to the available regulation capability of conventional generators in operation. Finally, the proposed method is verified and compared with conventional convolution method in the improved IEEE-RTS 79 system.
\end{abstract}

CrossCheck date: 8 December 2014

Received: 7 October 2014 / Accepted: 11 March 2015/Published online: 12 July 2015

(C) The Author(s) 2015. This article is published with open access at Springerlink.com

$\bowtie$ Ming ZHOU

zhouming@ncepu.edu.cn

Tingchao JIN

jintingchao@ncepu.edu.cn

Gengyin LI

ligy@ncepu.edu.cn

1 State Key Laboratory for Alternate Electrical Power System with Renewable Energy Sources, North China Electric Power University, Beijing, China
Keywords Universal generating function (UGF), Chronological characteristics, Environment cost, Multipleperiod multiple-state wind power model, Wind power accommodation

\section{Introduction}

Global climate change is a major challenge for the sustainable development of human society. Among the large amount of factors contributing to global warming, the increasing greenhouse gas emission caused by human activity is the most significant. Because of China's coaldominated energy structure, the current emissions of carbon dioxide mainly come from the energy sector, especially the electric power industry. Therefore, in order to achieve low-carbon economy, electric power industry is bound to become the main force for reducing the emission of carbon dioxide [1, 2].

At present, as the most important clean energy, largescale integration of wind power is helpful to improve the current power structure, which is the important means to achieve low-carbon electricity. Unlike traditional generation sources, wind power output is highly fluctuating, intermittent and limited controllable. These features have obvious influences on the reliability of power system operation [3-6]. Therefore, it is of great importance to effectively assess the impact of large-scale wind power integration on the reliability of power system operation. And based on which a reasonable power generation schedule is given.

As an effective computing tool, the probabilistic production simulation of power system can effectively optimize the operation of generators taking the randomness arising from generators into consideration. It can schedule 
the generator outputs, calculate the production cost and the reliability indices of power system operation [7, 8]. With the development of the wind power and other new energy power generation, the randomness of power system is further dominant, which makes power system probabilistic production simulation more important in power system planning and operation.

The current power system probabilistic production simulation with wind farms is based on equivalent load duration curve. It has apparent limitations without considering the time series information which makes it difficult to accurately describe the volatility and randomness of wind power, as well as the time-varying characteristics of load [9, 10]. Reference [11] combined the equivalent energy function method with frequency duration method and proposed an equivalent power frequency method to assess the impact of wind farm on the start-off of conventional unit. To a certain extent, the method retains some time-sequence information. But it is not enough to describe the characteristics of wind power and assess the impact of large-scale wind power integration on power system operation and reliability. References [12,13] proposed a method based on the time-series load curve which makes power system probabilistic production simulation able to consider the constraints associated with time. Based on sequence theory, References [14, 15] proposed a power system probabilistic production simulation which is suitable for electricity market with considering of the demand and supply uncertainty.

UGF is a highly efficient computing tool handling discrete random variable. Because of its advantage in computation, UGF is widely used in reliability assessment of multiple-state systems. As the generator capacity distribution is discrete, the output of a power system can be regarded as a multiple-state system. Based on this characteristic, the UGF-based probabilistic production simulation is proposed in this paper. The simulation is based on the time-series of wind power and load. The proposed method has the following advantages compared with the previous ones. Firstly, the multiple-period multiple-state wind farm model is divided into several modes and each mode has several sub-periods, so the proposed model can more accurately describe the wind farm output. Secondly, for environmental protection and low carbon demand, the proposed method considers the emission problem from the system operation aspect. The scheduling order of the generator is arranged according to the total cost including production cost and environmental cost. Thirdly, the wind power accommodation and curtailment is synergistically considered according to the available regulation capability of conventional generators on operation. The effectiveness and the superiority of the proposed algorithm are verified on the improved IEEE-RTS 79 system.

\section{Universal generating function}

The core idea of UGF is to express the discrete random variables in polynomial form. It defines polynomial assemble operator according to the algorithm of discrete random variables, and then the final result can be obtained by recursive computation. The details of UGF are described in $[16,17]$. The following is only a brief introduction. Here it is assumed that $X_{1}$ and $X_{2}$ are two random variables and their corresponding probability function $\operatorname{Pr}\{\cdot\}$ can be expressed as

$\operatorname{Pr}\left\{X_{1}=x(1, i)\right\}=p(1, i) 1 \leq i \leq k_{1}$

$\operatorname{Pr}\left\{X_{2}=x(2, j)\right\}=p(2, j) 1 \leq j \leq k_{2}$

where $x(1, i)$ is the value of the $i^{\text {th }}$ state of $X_{1} ; p(1, i)$ is the probability of $X_{1}=x(1, i) ; x(2, j)$ is the value of the $j^{\text {th }}$ state of $X_{2} ; p(2, j)$ is the probability of $X_{2}=x(2, j) ; k_{1}$ is the state number of $X_{1} ; k_{2}$ is the state number of $X_{2}$.

And the two random variables expressed in UGF model are

$u_{1}(z)=\sum_{i=1}^{k_{1}} p_{(1, i)} z^{x_{(1, i)}}$

$u_{2}(z)=\sum_{j=1}^{k_{2}} p_{(2, j)} z^{x_{(2, j)}}$

where $u_{1}(z)$ is the UGF model of $X_{1} ; u_{2}(z)$ is the UGF model of $X_{2} ; z$ itself has no obvious meaning and value, its main function is used for differentiating the value and probability of random variables, the index part of $z$ is composed by the values of random variables, and the coefficients of $z$ are the probabilities of random variables.

If $X_{1}$ and $X_{2}$ are independent of each other, their functional operation result will be a discrete random variable which can be obtained through the operation of UGF. For example, if $X_{3}$ equals to $X_{1}$ plus $X_{2}$, then $X_{3}$ can be expressed in UGF model as

$$
\begin{aligned}
& u_{3}(z)=\otimes\left(u_{1}(z), u_{2}(z)\right)=\sum_{i=1}^{k_{1}} \sum_{j=1}^{k_{2}} p_{(1, i)} \\
& p_{(2, j)} z^{x(1, i)+x(2, j)}=\sum_{s=1}^{k_{3}} p_{(3, s)} z^{x(3, s)}
\end{aligned}
$$

where $\otimes$ is a summation operator with respect to random variables; $u_{3}(z)$ is the UGF model of $X_{3} ; x(3, s)$ is the value of the $s^{\text {th }}$ state of $X_{3} ; p(3, s)$ is the probability of $X_{3}=x(3, s) ; k_{3}$ is the state number of $X_{3}$.

General generating function has a great advantage in dealing with discrete random variables. If $X_{1}$ and $X_{2}$ represent the output distributions of two generators, Equation (5) clearly expresses the distributions of two generator 
outputs. In addition, in the process of the probabilistic production simulation in power system, the complex convolution calculation can be replaced by simple polynomial calculation which greatly improves the computational efficiency.

\section{Modeling of wind power}

Reasonable modeling of wind power is the key for the establishment of the probabilistic production simulation in wind power integrated power system. In the current study, the modeling of wind power can be divided into a deterministic model and a random model. Wind power model in [11] is the deterministic model. Based on the wind speed sequence, wind power is obtained by the function relation between power and wind speeds. Here the wind power sequence is separated from the time-series load curve. The deterministic method cannot reflect the randomness of wind power. Random modeling of wind power mainly includes the multiple-state model and Monte Carlo simulation method. However, Monte Carlo method has the disadvantage of taking too long to calculate. The multiplestate model can better reflect the randomness of wind power, but it uses one probability distribution of wind power in all periods of time, which means that wind power is supposed to have the same volatility in any period of time. In fact, the probability distribution of wind power is different from time to time. Therefore, the model needs to be further improved. For this reason, a multiple-period multiple-state model is proposed based on the multiplestate model in this paper.

Obviously, wind power has seasonal characteristics, and its probability distribution is quite different in different periods in one day. So the proposed model is divided into $M$ modes according to season or month, and each mode is divided into $Q$ sub-periods.

Assuming that the capacity of wind farm is $P_{C}$, and it is divided into $\mathrm{N}$ status, then the states of wind power can be expressed as

$$
\begin{aligned}
P_{w} & =\left\{P_{1}, P_{2}, \ldots, P_{N}\right\} \\
& =\left\{0, \Delta P, 2 \Delta P, \ldots,(N-1) \Delta P \mid \Delta P=\frac{P_{C}}{N-1}\right\}
\end{aligned}
$$

where $P_{\mathrm{w}}$ is the set of wind powers; $\Delta P$ is the step length; $P_{i}(1 \leq i \leq N)$ is the $i^{\text {th }}$ state of $P_{w}$.

Based on the mathematical statistics, the probability $p$ of each state can be obtained by

$$
p_{w}=\left\{p_{1}, p_{2}, \ldots, p_{N} \mid \sum_{n=1}^{N} p_{n} s=1\right\}
$$

The UGF model of wind power is

$u_{\mathrm{Wm}}(z, t)=\sum_{n=1}^{N} p_{\mathrm{Wm}, n}(t) z^{P_{\mathrm{Wm}, n}(t)}$

where $u_{\mathrm{Wm}}(z, t)$ is the UGF model of wind power; $P_{\mathrm{Wm}, n}(t)$ and $p_{\mathrm{Wm}, n}(t)$ are the value and its probability of state $n$ in mode $m$ of wind power, respectively.

\section{Probabilistic production simulation for wind power integrated power system based on UGF}

\subsection{Power generation cost analysis}

In the process of probabilistic production simulation of power system, the system generation cost is determined by the generator scheduling order. Existing literatures only consider the fuel cost and the operation and maintenance cost, but take no account of the effects of pollutants. For large-scale wind power integrated power system, the existing power generation plan must be improved. We consider the influence of the pollutants and take it as the governance cost, called the environmental cost. The order of the unit schedule is decided by the comprehensive generation $\operatorname{cost} C$, including the fuel cost $C_{\mathrm{f}}$, the operation and maintenance cost $C_{\mathrm{O \& M}}$ and the environmental cost $C_{\mathrm{e}}$ : $C=C_{\mathrm{f}}+C_{\mathrm{O} \& \mathrm{M}}+C_{\mathrm{e}}$

\subsection{UGF model of conventional unit}

In actual power system operation, conventional unit partial failure and individual auxiliary equipment failure may occur. Under failure situation, the generator does not necessarily have to exit the operation, but its available generation capacity is less than the rated output. That is to say, the generator is operating in a degraded capacity state. Therefore, conventional units should be considered as multiple states rather than two states. In order to ensure the accuracy of simulation, the model also takes the planned maintenance of units into consideration.

Assuming that the conventional unit $g$ has $k_{g}$ states in total, then its UGF model is

$u_{g}(z, t)=\left(1-M_{g}(t)\right) \sum_{j=1}^{k_{g}} p_{g, j}(t) z^{c_{g, j}(t)}+M_{g}(t) z^{0}$

where $u_{\mathrm{g}}(z, t)$ is the UGF model of unit $g ; c_{g, j}(t)$ and $p_{g, j}(-$ $t)$ are the power and corresponding probability when generator $g$ is operating at moment $t$, respectively; $M_{g}(t)$ is the parameter reflecting unit planned maintenance. If unit $g$ is arranged to be repaired, $M_{g}(t)$ equals to 1 ; otherwise, $M_{g}(t)$ equals to 0. 


\subsection{Process of probabilistic production simulation}

In the process of probabilistic production simulation of power system, the generating capacity of the whole power system is considered as a multiple-state system. Taking both accuracy and complexity into account, $1 \mathrm{MW}$ is taken as a basic unit which corresponds to a state in this paper. On this basis, the UGF algorithm is introduced to run the probabilistic production simulation of power system.

As a kind of clean pollution-free energy source, wind power is prioritized to operate in the process of probabilistic production simulation of power system. Then conventional generators are put into operation according to their total generation costs.

Assuming that generator $k$ is put into operation at moment $t$, the system power UGF model $u_{\mathrm{S}, k}(z, t)$ is

$$
\begin{aligned}
u_{\mathrm{S}, k}(z, t) & =\otimes\left(u_{1}(z, t), u_{2}(z, t), \ldots, u_{k}(z, t)\right) \\
& =\sum_{i=1}^{S_{k}} p_{k, i}(t) z^{s_{k, i}(t)}
\end{aligned}
$$

where $S_{k}$ is the state number of system power when generator $k$ is put into operation; $s_{k, i}(t)$ and $p_{k, i}(t)$ are generating capacity and the probability of state $i$ when generator $k$ is put into operation, respectively.

If $L(t)$ is hourly load series, for generator $k$, the loss of load probability (LOLP) $L_{\mathrm{OLP} k}(t)$ and the expected energy not served(EENS) $E_{\text {ENS } k}$ are

$$
\begin{aligned}
L_{\mathrm{OLP} k}(t) & =\sum_{S_{k, i}(t)<L(t)} p_{k, i}(t) \\
E_{\mathrm{ENS} k}(t) & =\sum_{s_{k, i}(t)<L(t)} p_{k, i}(t)\left(L(t)-s_{k, i}(t)\right) \Delta t
\end{aligned}
$$

where $\Delta t$ is the simulation interval. In this paper $\Delta t=1$ hour.

When the supply cannot meet the demand after generator $k$ being put into operation, generator $k+1$ will be running. So $\mathrm{L}_{\mathrm{OLP} k}(t)$ is also the probability of generator $k+1$ being put into operation, which is called the loading rate.

$L_{\mathrm{R}_{k+1}}(t)=L_{\mathrm{OLPk}}(t)$

where $L_{\mathrm{R}_{k+1}}(t)$ is the probability of generator $k+1$ being put into operation at moment $t$.

And we can also expected generating energy of generator $k E_{k}(t)$ by

$E_{k}(t)=E_{\mathrm{ENS} k}(t)-E_{\mathrm{ENS} k-1}(t)$

Assuming that the total number of hours is $T$, the total generating energy $E_{k, \text { all }}$ of generator $k$ is

$E_{k, \mathrm{all}}=\sum_{t=1}^{T} E_{k}(t)$
When all the generators are put into operation, the system power UGF model $u_{\mathrm{S}, \text { all }}(z, t)$ is

$u_{\mathrm{S}, \mathrm{all}}(z, t)=\sum_{i=1}^{S} p_{i}(t) z^{s_{i}(t)}$

where $S$ is the state number of system power when all the generators are in operation; $s_{i}(t)$ and $p_{i}(t)$ are the generating capacity and probability of state $i$ when all the generators are in operation, respectively.

And the LOLP of power system at moment $t L_{\mathrm{OLP} \text {,sys- }}$ tem $(t)$ and the EENS of power system at moment $t$ $E_{\mathrm{ENS}, \mathrm{system}}(t)$ can be obtained as

$L_{\mathrm{OLP}, \mathrm{system}}(t)=\sum_{s_{i}(t)<L(t)} p_{i}(t)$

$E_{\mathrm{ENS}, \text { system }}(t)=\sum_{s_{i}(t)<L(t)} p_{i}(t)\left(L(t)-s_{i}(t)\right) \Delta t$

The power system reliability indices during the whole simulation period are

$L_{\mathrm{OLP}, \text { sum }}=\frac{\sum_{t=1}^{T} L_{\mathrm{OLP}, \text { system }}(t)}{T}$

$E_{\mathrm{ENS}, \mathrm{sum}}=\sum_{t=1}^{T} E_{\mathrm{ENS}, \mathrm{system}}(t)$

where $L_{\mathrm{OLP} \text {,sum }}$ and $E_{\mathrm{ENS} \text {,sum }}$ are the LOLP and EENS of power system during the whole simulation period, respectively.

The process of the probabilistic production simulation of the proposed power system is shown in Fig. 1.

\section{Assessment of wind power accommodation and curtailment}

As a kind of clean energy, the large-scale development and utilization of wind power is an important guarantee to achieve low-carbon electricity. More wind power means less conventional power generation. It is meaningful for both economy and environment. However, in fact, not all wind power can be accommodated by power system. Therefore, improving the penetration of wind power on the basis of the assessment of wind power accommodation is very necessary.

The outputs of conventional generators are bound by minimum output and maximum output. In general, the minimum output of thermal power unit is $70 \%$ of the rating, a few units are up to $50 \%$ or $60 \%$, and the steam turbine is $10 \%$ or $15 \%$ of the rating. Obviously, at any time the system can accept the largest wind power which is equal to the load minus the minimum outputs of all the 


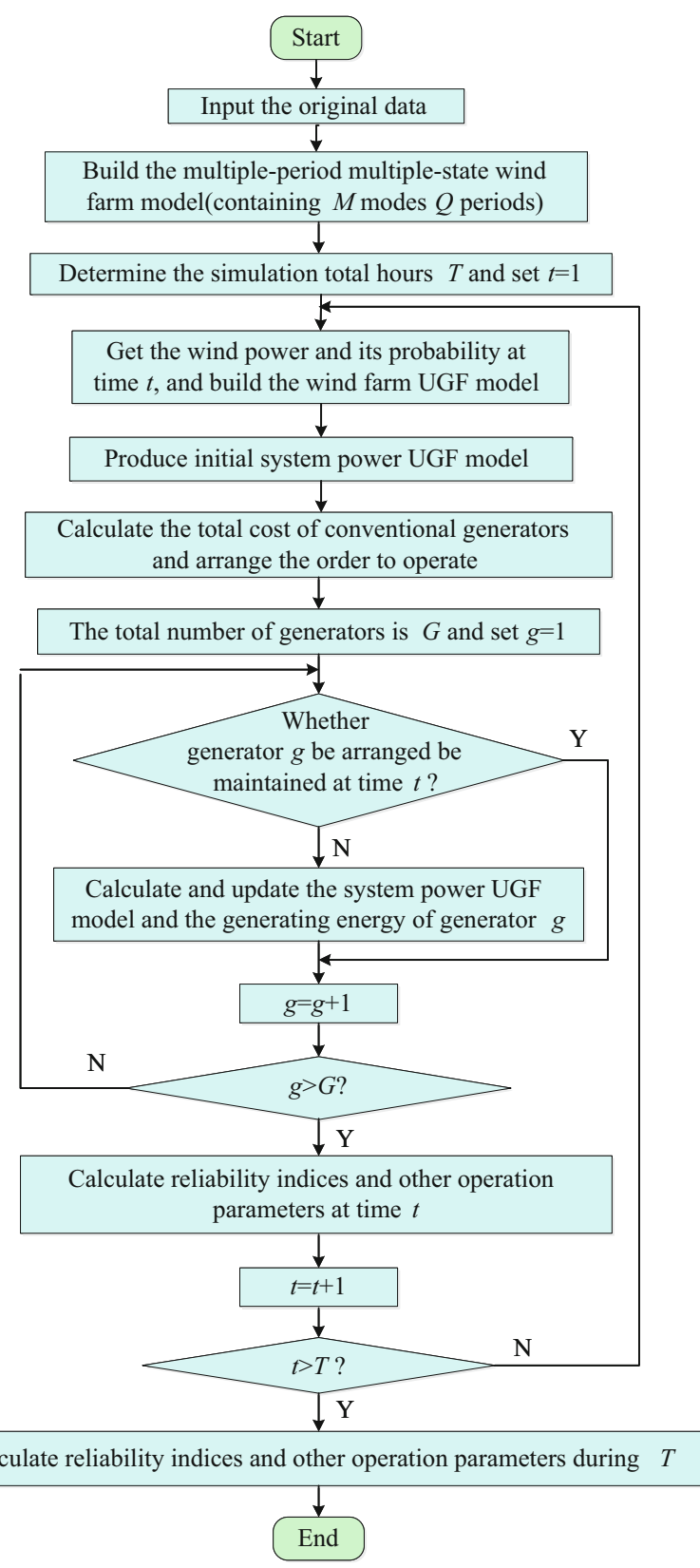

Fig. 1 Flowchart of probabilistic production simulation of power system considering wind farms

generators in operation. It is called the wind power accommodation capability [18]. Then, the wind power to be accommodated at moment $t$ is given by

$W_{\mathrm{RS}}(t)=L(t)-P_{\mathrm{S} \min }(t)$

where $W_{\mathrm{RS}}(t)$ is the wind power accommodation capability of system at time $t ; L(t)$ is the load at time $t ; P_{\mathrm{Smin}}(t)$ is the minimum output of all the generators in operation at time $t$.

Therefore, at any time, the generators in operation determine wind power accommodation. Assuming that the value of wind power is $P_{\mathrm{W}}(t)$, when $P_{\mathrm{W}}(t)>W_{\mathrm{RS}}(t)$, the part of wind power which can be accepted is $W_{\mathrm{RS}}(t)$, while the part of the beyond will be curtailed.

For medium and long term operation simulation, the operating condition of generators cannot be completely deterministic. Therefore, $P_{\mathrm{Smin}}(t)$ is determined by the loading rate and the forced outage rate of generators.

$P_{\text {Smin }}(t)=\sum_{g=1}^{G} R_{g}(t)\left(1-F_{g}\right) P_{g \min }$

where $G$ is the number of generators; $F_{g}, P_{g \min }, R_{g}(t)$ are the forced outage rate, the minimum output and the loading rate of generator $\mathrm{g}$, respectively.

The probability and the expected electricity of the curtailed wind power at moment $t$ in mode $m$ are

$$
\begin{aligned}
& p_{\mathrm{a}}(t)=\sum_{P_{\mathrm{Wm}, n}(t)>W_{\mathrm{RS}}(t)} p_{\mathrm{Wm}, n}(t) \\
& P_{\mathrm{Aexp}}(t)=\sum_{P_{\mathrm{Wm}, n}(t)>W_{\mathrm{RS}}(t)}\left(P_{\mathrm{Wm}, n}(t)-W_{\mathrm{RS}}(t)\right) p_{\mathrm{Wm}, n}(t)
\end{aligned}
$$

where $p_{\mathrm{a}}(t)$ and $P_{\text {Aexp }}(t)$ are the probability and the expected electricity of the curtailed wind power at moment $t$, respectively.

\section{Case study}

A simulation example is established in modified IEEERTS 79 system in this paper. The installed generating capacity is $3405 \mathrm{MW}$ [19]. And the operating parameters of generators are listed in Table 1. The annual maximum load is $2850 \mathrm{MW}$. The data of reliability, fuel cost and operation and maintain costs are referred in [19] while the environmental cost is referred in [20]. In addition, a wind farm is added to the test system, the installed generating capacity of wind farm is $400 \mathrm{MW}$. The historical data of an offshore wind farm, are shown in Table 1.

\subsection{Validation for correctness of the proposed algorithm}

To illustrate the correctness of the algorithm proposed in this paper, the results of the proposed algorithm and the method proposed in [21] are compared in Table 2. This is the result of probabilistic production simulation of power system without wind power. The results of two algorithms are almost the same, which proves the correctness of the proposed method.

The proposed algorithm with simple polynomial operation instead of complicated convolution calculation greatly improves the computation efficiency. In addition, 
Table 1 Operating parameters of generators

\begin{tabular}{|c|c|c|c|c|c|c|}
\hline Number & Type & Number of units & Capacity (MW) & Forced outage rate & $C_{\mathrm{f}}+C_{\mathrm{O \& M}}(\$ / \mathrm{MWh})$ & $C \mathrm{e}(\$ / \mathrm{MWh})$ \\
\hline 1 & Oil & 5 & 12 & 0.02 & 28.5 & 5 \\
\hline 2 & Gas turbine & 4 & 20 & 0.10 & 48.5 & 2.5 \\
\hline 3 & Hydro & 6 & 50 & 0.01 & 0.2 & 0 \\
\hline 4 & Coal & 4 & 76 & 0.02 & 15.3 & 13 \\
\hline 5 & Oil & 3 & 100 & 0.04 & 23.8 & 5 \\
\hline 6 & Coal & 4 & 155 & 0.04 & 12.44 & 12 \\
\hline 7 & Oil & 3 & 197 & 0.05 & 22.78 & 5 \\
\hline 8 & Coal & 1 & 350 & 0.08 & 12.1 & 13 \\
\hline 9 & Nuclear & 2 & 400 & 0.12 & 6.3 & 0.4 \\
\hline
\end{tabular}

the proposed method can deal with chronological wind power and demand, and the system operation can be simulated hour by hour, which makes the simulation results more detailed and ample. On this basis, it provides a more powerful simulation and analysis tool. When large-scale wind power penetrates into power grid, it is important to assess both the impact of wind power on grid operation and the consumption of wind power effectively. However, wind power and load are different from time to time, so it is necessary to simulate the system balance between supply and demand hour by hour. However, traditional methods like the method in [21] can only obtain the total output of units and statistical reliability indices in the whole simulation period rather than every hour. Compared with traditional method, the proposed method can calculate the power system operation indicators at any moment during the simulation period, as well as the probability and expectations of wind power curtailment. The assessment method for wind power accommodation and curtailment is used in the following case study.

Table 2 Comparison between two algorithms

\begin{tabular}{lrrr}
\hline Operating parameter & \multicolumn{1}{l}{$\begin{array}{l}\text { Proposed } \\
\text { method }\end{array}$} & $\begin{array}{l}\text { Convolution } \\
\text { method in [21] }\end{array}$ \\
\hline Units supplied energy of & 1 & 1148.93 & 1149 \\
generators 1 to 9 (MWh) & 2 & 885.45 & 885 \\
& 3 & 2594592.00 & 2594592 \\
& 4 & 680453.31 & 680454 \\
& 5 & 18639.88 & 18639 \\
& 6 & 3002400.40 & 3002401 \\
& 7 & 333287.15 & 333287 \\
& 8 & 2521737.39 & 2521737 \\
& 9 & 6142753.90 & 6142754 \\
Total produced energy (MWh) & 15295898.42 & 15295900 \\
$E_{\text {ENS,sum }}(\mathrm{MWh})$ & 1176.30 & 1176 \\
$L_{\text {OLP,sum }}$ & 0.0011 & \\
\hline
\end{tabular}

\subsection{Probabilistic production simulation in a month}

We take a month probabilistic production simulation as an example. Additional parameters of generators are shown in Table 3. The results of probabilistic production simulation in May are listed in Table 4.

The results in Table 4 show that power system probabilistic production simulation considering the environmental cost makes the power generation plan change. When considering the environment cost, the total cost of generators will change, which affects the order of the generating set. Although the total power generation and operation indicators remain unchanged, the allocation of power generation in different generators is changed. It can be seen from Table 4 that the power outputs of Unit 4 and Unit 7 have changed a lot, which makes the fuel cost and operation cost increase while the environmental cost becomes lower. It shows that the proposed method takes energy conservation, emissions and pollution reduction into account comprehensively.

\subsection{Assessment of wind power curtailment}

This section assesses the consumption of wind power based on the probabilistic production simulation on

Table 3 Additional operating parameters of generators

\begin{tabular}{llll}
\hline Number & $\begin{array}{l}\text { Capacity } \\
\text { (MW) }\end{array}$ & $\begin{array}{l}\text { Minimum } \\
\text { technology output } \\
\text { capacity (\%) }\end{array}$ & $\begin{array}{l}\text { Number of } \\
\text { planned } \\
\text { maintenance }\end{array}$ \\
\hline 1 & 12 & 0.65 & 0 \\
2 & 20 & 0.20 & 0 \\
3 & 50 & 0 & 0 \\
4 & 76 & 0.65 & 0 \\
5 & 100 & 0.65 & 0 \\
6 & 155 & 0.65 & 0 \\
7 & 197 & 0.65 & 0 \\
8 & 350 & 0.65 & Once in the 3rd week \\
9 & 400 & 0.65 & 0 \\
\hline
\end{tabular}


Table 4 Probabilistic production simulation of a month

\begin{tabular}{|c|c|c|c|}
\hline Operating parameter & & $\begin{array}{l}\text { Considering } \\
\text { environment } \\
\text { cost }\end{array}$ & $\begin{array}{l}\text { Without } \\
\text { considering } \\
\text { environment cos }\end{array}$ \\
\hline \multirow{9}{*}{$\begin{array}{l}\text { Units supplied energy of } \\
\text { generators } 1 \text { to } 9 \\
\text { (MWh) }\end{array}$} & 1 & 155.10 & 155.10 \\
\hline & 2 & 120.55 & 120.55 \\
\hline & 3 & 213840.00 & 213840.00 \\
\hline & 4 & 11680.51 & 71774.56 \\
\hline & 5 & 2627.93 & 2627.93 \\
\hline & 6 & 277073.69 & 277073.69 \\
\hline & 7 & 101306.73 & 41212.67 \\
\hline & 8 & 2521737.39 & 156260.58 \\
\hline & 9 & 505583.86 & 505583.86 \\
\hline \multicolumn{2}{|l|}{$\begin{array}{l}\text { Total produced energy } \\
\text { (MWh) }\end{array}$} & 1268748.95 & 1268748.95 \\
\hline \multicolumn{2}{|l|}{$\begin{array}{l}\text { Wind farm supplied energy } \\
\text { (MWh) }\end{array}$} & 57820.27 & 57820.27 \\
\hline \multicolumn{2}{|l|}{$L_{\mathrm{OLP}, \text { sum }}$} & 0.0018 & 0.0018 \\
\hline \multicolumn{2}{|l|}{$E_{\mathrm{ENS}, \text { sum }}(\mathrm{MWh})$} & 1159.08 & 1159.08 \\
\hline \multicolumn{2}{|l|}{ Fuel and operation cost $(\$)$} & 11125996.88 & 10676493.36 \\
\hline \multicolumn{2}{|l|}{ Environment cost $(\$)$} & 6509475.75 & 6990228.17 \\
\hline \multicolumn{2}{|l|}{ Total cost $(\$)$} & 17635472.63 & 17666721.53 \\
\hline
\end{tabular}

Table 5 Probabilistic production simulation of one day

\begin{tabular}{llll}
\hline $\begin{array}{l}\text { Time } \\
\text { period }\end{array}$ & $\begin{array}{l}\text { Wind power } \\
\text { accommodation } \\
\text { capacity (MW) }\end{array}$ & $\begin{array}{l}\text { Probability of } \\
\text { curtailed wind } \\
\text { power }\end{array}$ & $\begin{array}{l}\text { Expectations energy } \\
\text { of curtailed wind } \\
\text { power }(\mathrm{MWh})\end{array}$ \\
\hline 1 & 429.07 & 0 & 0 \\
2 & 374.99 & 0 & 0 \\
3 & 315.07 & 0.024 & 0.33 \\
4 & 296.06 & 0.031 & 0.28 \\
5 & 292.36 & 0.006 & 0.15 \\
6 & 274.48 & 0.100 & 5.50 \\
7 & 269.28 & 0.074 & 1.61 \\
8 & 318.19 & 0.067 & 2.96 \\
9 & 481.96 & 0 & 0 \\
10 & 514.14 & 0 & 0 \\
\hline
\end{tabular}

Saturday of the 19th week. The results of probabilistic production simulation are shown in Table 5, in which the simulation results from time periods 1 to 10 are shown (each time period presents an hour), and wind power curtailment only occurs at time periods 3 to 8 .

The results in Table 5 show that not all wind power is dispatched. Wind power may be occasionally abandoned. The situation of large amount of wind power penetrating into power grid may frequently occur. The proposed method can realize the production simulation as well as assess wind power accommodation and curtailment.

\section{Conclusion}

Based on the theory of UGF, power system probabilistic production simulation considering wind power is proposed in this paper. The method is based on the time-series of wind power and load, thus the method can reflect the timevarying characteristics of wind power and load. In addition, taking the planned maintenance of generators into account, it can accurately describe the actual operation. Wind power modeling is the basis of the algorithm for probabilistic production simulation of wind power integrated power system. Multiple-period multiple-state model is adopted in this paper for its characteristic of well-reflecting the randomness and volatility of wind power. The proposed method considers the pollutant emission in the process of power system probabilistic production simulation, and is capable of assessing wind power accommodation as well as achieving the probability and expectations of wind power curtailment. Furthermore, the proposed method has potential in calculating wind power capacity of credibility.

Acknowledgments This work is supported by National High Technology Research and Development Program of China (863 Program) (No. 2012AA050208) and the Program of the National Natural Science Foundation of China (No. 51177043).

Open Access This article is distributed under the terms of the Creative Commons Attribution License which permits any use, distribution, and reproduction in any medium, provided the original author(s) and the source are credited.

\section{References}

[1] Kang CQ, Chen QX, Xia Q (2009) Prospects of low-carbon electricity. Power Syst Technol 33(2):1-7 (in Chinese)

[2] Kang CQ, Zhou TR, Chen QX et al (2009) Assessment model on low-carbon effects of power grid and its application. Power Syst Technol 33(17):1-7 (in Chinese)

[3] Wang HC, Lu ZX, Zhou SX (2005) Research on the capacity credit of wind energy resources. Proc CSEE 25(10):103-106 (in Chinese)

[4] Billinton R, Huang D (2011) Incorporating wind power in generating capacity reliability evaluation using different models. IEEE Trans Power Syst 26(4):2509-2517

[5] Chen SY, Dai HZ, Bai XM et al (2000) Reliability model of wind power plants and its application. Proc CSEE 30(3):26-29 (in Chinese)

[6] Lei YZ (2003) Studies on wind farm integration into power system. Automat Electr Power Syst 27(8):84-89 (in Chinese)

[7] Wang XF, Wang XL (2003) Probabilistic production simulation method and its application. Automat Electr Power Syst 27(8):10-15 (in Chinese)

[8] Yu RY, Gao S (2012) Applications of probabilistic production simulation in power system. Power Syst Protect Control 40(11):149-154 (in Chinese)

[9] Chen SY, Dai HZ, Bai XM et al (2000) Power system probabilistic production simulation including wind power plants. Electr Power 33(3): 30-31, 69 (in Chinese) 
[10] Wang XF, Dai HZ, Thomas RJ (1984) Reliability modeling of large wind farms and associated electric utility interface systems. IEEE Trans Power Appar Syst 103(3):569-575

[11] Zhang JT, Chen HZ, Hu ZC et al (2009) Power system probabilistic production simulation including wind farms. Proc CSEE 29(28):34-39 (in Chinese)

[12] Xia Q, Wang SJ, Xiang ND (1994) The probabilistic power system production simulation based on chronological load curve. Proc CSEE 14(3):21-28 (in Chinese)

[13] Xia Q, Wang SJ, Xiang ND et al (1998) Hydro station's probabilistic production simulation. Proc CSEE 18(6):429-433 (in Chinese)

[14] Kang CQ, Xia Q, Xiang ND et al (2002) Sequence-based analysis of probabilistic production cost simulation. Proc CSEE 22(4):8-12 (in Chinese)

[15] Kang CQ, Xia Q, Xiang ND et al (2002) Implement of probabilistic production cost simulation algorithm based on sequence operation theory. Proc CSEE 22(9):6-11 (in Chinese)

[16] Levitin G (2005) The universal generating function in reliability analysis and optimization. Springer-Verlag London Ltd, London

[17] Lisnianski A, Levitin G (2003) Multi-state system reliability assessment, optimization, applications. World Scientific, Singapore

[18] Lü Q, Wang W, Han S et al (2013) A New evaluation method for wind power curtailment based on analysis of system regulation capability. Power Syst Technol 37(7):1887-1893 (in Chinese)

[19] Probabilistic Methods Subcommittee (1979) IEEE reliability test system. IEEE Trans Power Appar Syst 98(6):2047-2054

[20] Lu H, Zhou H (2004) Environmental cost analysis of power plants. Environ Econ 4:51-54 (in Chinese)
[21] Allan RN, Billinton R, Abdel-Gawad NMK (1986) The IEEE reliability test system-extensions to and evaluation of the generating system. IEEE Trans Power Syst 1(4):1-7

Tingchao JIN was born in Zhejiang Province, China. He received the B.S. degree in Electrical Engineering from North China Electricity Power University (NCEPU) in 2012. Currently, he is pursuing the M.S. degree in Electrical Engineering in NCEPU. His main research interest is power system reliability analysis and optimal operation.

Ming ZHOU was born in Hubei Province, China. She received the B.S., M.S. and Ph. D. degrees in Electrical Engineering from North China Electricity Power University (NCEPU) in 1989, 1992 and 2006 respectively. Since 1992, Dr. Zhou has been with the School of Electrical and Electronic Engineering at NCEPU, where she is currently a professor. Her areas of interest include power system analysis and reliability, power system economics, and power quality analysis.

Gengyin LI was born in Hebei Province, China. He received the B.S., M.S. and $\mathrm{Ph}$. D. degrees, all in Electrical Engineering from North China Electricity Power University (NCEPU) in 1984, 1987, and 1996 respectively. Since 1987, Dr. Li has been with the School of Electrical and Electronic Engineering at NCEPU, where he is currently a professor. His areas of interest include power system economics, power quality analysis and control, and new transmission and distribution technologies. 